\title{
Participation of the Tightly-Bound (Putative Cytoskeleton-Bound) Polysomes in Translation during Germination of Dormant and Non-Dormant Cereal Caryopses
}

Stanisław Weidner*,a, Dorota Łukaszewicz ${ }^{\mathrm{a}}$ and Ryszard Amarowicz ${ }^{\mathrm{b}}$

a Department of Biochemistry, Faculty of Biology, Warmia and Masuria University in Olsztyn. Kortowo, Pl. Łódzki 3, PL - 10-718 Olsztyn, Poland.

Fax: 4889 - 52739 08. E-mail: weidner@art.olsztyn.pl

b Division of Food Science, Institute of Animal Reproduction and Food Research of Polish Academy of Sciences, ul. Tuwima 10,10-718 Olsztyn 5, P. O. Box 55, Poland

* Author for correspondence and reprint requests

Z. Naturforsch. 55c, 23-29 (2000); received August 17/October 1, 1999

Hordeum vulgare L., Triticosecale, Cytoskeleton-Bound Polysomes, Dormancy, Germination, Abscisic Acid

Research was done on dormant and non-dormant barley cv. Ars caryopses and triticale cv. Grado caryopses treated and non-treated with abscisic acid (ABA). During germination higher participation of populations of so-called tightly-bound polysomes (TBP) in embryos of dormant barley caryopses was observed, as well as their high metabolic activity. In embryos of triticale caryopses of which dormancy was imposed in an artificial way by ABA $(100 \mu \mathrm{M})$, the strongest incorporation of ${ }^{14} \mathrm{C}$-amino acids into nascent polypeptide chains in vivo was found in population of TBP, as well as the highest participation among three of the studied fractions (free polysomes, membrane-bound polysomes and tightly-bound polysomes). These results may indicate the significant role of TBP (putative cytoskeleton-bound polysomes - CBP) in maintaining dormancy during imbibition of cereal caryopses.

\section{Introduction}

Harvest-ripe cereal grains may not germinate immediately. While this is advantageous in the field, protecting the crop against sprouting in the ear, it is clearly a problem in relation to malting, which depends on active germination. Glumless caryopses such as rye, triticale and wheat are especially prone to precocious germination. This phenomenon sometimes causes great world-wide losses (Derera, 1990). The mechanism of dormancy is not fully understood (Simpson, 1990; Bewley and Black, 1994).

It has recently become clear, that the initiation of dormancy involves the action of ABA (Bewley, 1997; Li and Foley, 1997). Initiation of dormancy may also depend on seed sensitivity to ABA (Weidner, 1987). Evidence that the degree of sensitivity to ABA is indeed important comes from studies on dormancy in wheat grains. Differences in susceptibility to pre-harvest sprouting occur among cultivars according to the intensity of dormancy. But though the dormancy varies, the ABA concentrations are similar (Walker-Simmons, 1987). Isolated embryos of both types (resistant and susceptible to sprouting) also germinate equ- ally well on water. Differences show up, however, in the presence of ABA. Those of the high-dormancy cultivar respond more to ABA (WalkerSimmons, 1988; Morris et al., 1989).

Major action of ABA in seeds (and other plant parts) is the regulation of gene expression, particularly the induction of several different kinds of polypeptides and the inhibition of genes for certain reserve mobilising enzymes (Dommes and Northcote, 1985; Jacobsen and Chandler, 1987; Skiver and Mundy, 1990). When ABA is acting to induce dormancy it also causes formation of a spectrum of proteins. Some of these proteins probably provoke the initiation of dormancy (Black, 1991). ABA-responsive genes are expressed more readily in embryos of dormant grains, raising the possibility that set of "dormancy proteins" exists. So far it has not been explained, what the function and mechanism of action of these proteins is.

Regulation of gene expression by ABA also occurs, at the post-transcriptional and/or the translational level (e.g. Bray, 1991). For example, osmotion, a salt-regulated gene product, acumulates in tobacco suspension cultures in response to $\mathrm{ABA}$ only in a low water potential environment even though the mRNA accumulates in response to 
ABA application at high and low water potentials (Singh et al., 1989). This indicates that ABA requires additional signals that are only present at low water potentials to regulate translation.

Lenk et al. (1977) suggested that the cytoskeleton of animal cells could serve as an attachment site for a subpopulation of polysomes, the cytoskeleton-bound polysomes (CBP). The fundamental role of the cytoskeleton in subcellular transport and localization of mRNAs in animals is widely accepted (St. Johnston, 1995). Since polysomes are the site of translation and thus mediate the final step in gene expression, their subcellular location is important for the ultimate density of their products. It is assumed that in animal cells free polysomes (FP) are involved primarily in the synthesis of cytosolic proteins, membrane-bound polysomes (MBP) are involved in the synthesis of secreted and sequestrated proteins and cytoskeleton-bound polysomes (CBP) in the synthesis of cytoskeletal, virial, or stress proteins (Elder and Morré, 1978; Adams et al., 1983; Hesketh and Pryme, 1991).

The objective of this research was to show the presumable role which population of the tightlybound polysomes (putative cytoskeleton-bound polysomes) may play in translation, during germination of dormant barley caryopses and treated with ABA triticale grains.

\section{Materials and Methods}

\section{Plant material, germination conditions and conditions of labelling}

The study was conducted on barley (Hordeum vulgare L.) $c v$. Ars and triticale (Triticosecale) $c v$. Grado cultivated in an experimental field of the Warmia and Masuria University in Olsztyn. Barley caryopses in full ripeness were collected and divided into two batches. One batch was examined immediately after harvest (dormant caryopses), the other batch was kept for eight months in a laboratory at $20^{\circ} \mathrm{C}$ and dry air. During eight months storage in the dry state, caryopses were completely released from dormancy. This batch (non-dormant caryopses), was also subjected to the same comparative investigations. Triticale caryopses collected in full ripeness, after releasing of (very shallow) dormancy, were treated with dif- ferent concentration of $\mathrm{ABA}(0,1,10$ and $100 \mu \mathrm{M})$ during germination.

The caryopses before germination were washed with tap water, placed for $3 \mathrm{~min}$ in a $1 \%$ solution of sodium hypochlorite and washed thoroughly with cool, redistilled sterile water. The materials were then subjected to $48 \mathrm{hrs}$ germination in water (or in ABA solutions) on Petri dishes in darkness at $21-22^{\circ} \mathrm{C}$. After 48 hrs germination barley caryopses were transferred into a solution of radioactive precursors and germinated for 6 hrs. Germination was conducted in the presence of $\left[{ }^{14} \mathrm{C}\right]$-amino acid hydrolysate $\left(3.7 \mathrm{MBq} \cdot \mathrm{ml}^{-1}\right)$ or $\left[{ }^{3} \mathrm{H}\right]$-uridine $\left(3.7 \mathrm{MBq} \cdot \mathrm{ml}^{-1}\right)$ and chloroamphenicol $\left(10 \mu \mathrm{g} \cdot \mathrm{ml}^{-}\right.$ ${ }^{1}$ ). At specific times, embryos (or germs) were isolated from grains, the nonincorporated precursor was carefully rinsed off, the embryo surfaces dried and then stored in liquid nitrogen until further study.

Triticale caryopses after initial $48 \mathrm{hrs}$ of germination in water or in ABA solutions $(1,10$ and $100 \mu \mathrm{M})$ were transferred into solution of $\left[{ }^{14} \mathrm{C}\right]$ amino acid hydrolysate $\left(3.7 \mathrm{MBq} \cdot \mathrm{ml}^{-1}\right)$ and chloramphenical $\left(10 \mu \mathrm{g} \cdot \mathrm{ml}^{-1}\right)$. Caryopses were germinated in the presence of radioactive precursors for $30 \mathrm{~min}$. Embryos (or germs) were isolated from grains after definite germination time, nonincorporated precursors was carefully rinsed off, the embryo surfaces dried and three polysome fractions were extracted from this plant material.

\section{Polysome isolation and sucrose gradient analysis of polysomes}

Germinating barley or triticale embryos were homogenized in buffer A consisting of $200 \mathrm{~mm}$ Tris [tris(hydroxymethyl)aminomethane]- $\mathrm{HCl}, \mathrm{pH} 8.5$, $50 \mathrm{~mm}$ potassium acetate, $25 \mathrm{~mm}$ magnesium acetate (Davies et al., 1972) filtered and centrifuged at $27000 \mathrm{xg}$ for $10 \mathrm{~min}$ to release the free polysomes (FP) into the supernatant. The pellet was extracted sequentially in buffer A supplemented with 2\% PTE (polyoxyethylene-10-tridecyl ether, a non-ionic detergent) to yield released MBP (membrane-bound polysomes). The supernatants were kept on ice and the tightly-bound polysomes retained in the pellets were solubilized in buffer $U$ consisting of buffer A supplemented with $2 \%$ PTE, 1\% DOC (sodium deoxycholate), $2 \mathrm{~mm}$ EGTA (ethylene glycol-bis $(\beta$-aminoethyl ethe- 
r) $N, N_{,} N^{\prime}, N^{\prime}$ - tetraacetic acid) and $100 \mu \mathrm{g} \cdot \mathrm{ml}^{-1}$ heparin, which is used to solubilize virtually all polysomes from any source (Abe et. al., 1992). After incubation for $10 \mathrm{~min}$, pellets were resuspended by vortexing using a grass rod in each tube, buffer $U$ extracts were recentrifuged for $10 \mathrm{~min}$ at $27000 \mathrm{xg}$. All the supernatants were layered on $4 \mathrm{ml}$ "pad" of $50 \%(\mathrm{w} / \mathrm{v})$ sucrose in buffer B (50 mм Tris- $\mathrm{HCl}, \mathrm{pH} 7.5 ; 20 \mathrm{~mm}$ potassium acetate, $10 \mathrm{~mm}$ magnesium acetate) and centrifuged for $3 \mathrm{~h}$ at $300000 \mathrm{xg}$ in a Beckman $65 \mathrm{Ti}$ rotor. The polysome pellets were rinsed in water and then resuspended in $1 \mathrm{ml}$ buffer $\mathrm{U}$. The resuspended polysomes were centrifuged at top speed (approx. $18000 \mathrm{xg}$ ) for $2 \mathrm{~min}$ in a microfuge prior to layering $0.2 \mathrm{ml}$ aliquots of supernatant on linear 15 to $60 \%(\mathrm{w} / \mathrm{v})$ sucrose gradients in buffer B. Separation of subunits, monosomes and polysomes was achieved by centrifugation at $122000 \mathrm{xg}$ in a Beckman SW-41 rotor for $75 \mathrm{~min}$. All operations were conducted at $0-4{ }^{\circ} \mathrm{C}$. Gradients were next scanned at $254 \mathrm{~nm}$ on an UA-5 flow recorder (ISCO, Lincoln, NE, USA). The percentage of polysomes in the total ribosomal preparation was calculated by xeroxing the $\mathrm{A}_{254}$ profile, drawing the base line (obtained by scanning a blank gradient) under the profile, and then cutting out and weighing the paper (uniform in thickens) representing the areas of monosomes and polysomes of the profiles. Quantitation of the ribosomes was done assuming that the absorbance (A) of a $1 \%$ solution of ribosomes (measured in a cuvette with a $1 \mathrm{~cm}$ optical path at 260) equals $\mathrm{A}_{260}=13.5$ (Gualerzi and Cammarano, 1969). Radioactvity was assayed using a Beckman LS-1801 liquid scintillation counter, applying Tritosol as the scintillaton (Fricke, 1973). All experiments were done at least in triplicate.

\section{Results and Discussion}

Participation of free membrane-bound and tightly-bound (putative cytoskeleton-bound) polysomes in the regulation of barley caryopses dormancy and germination

Using conventional polysome isolation buffers were obtained two populations of polysomes, by homogenizing embryos in buffer $\mathrm{A}$ - to yield free polysomes (FP) and extracted from pellet in buffer
A + PTE - membrane bound polysomes (MBP) (Davies et al., 1972; Larkins and Davies, 1975). It appeared however, that some polysomes still retained in pellet, the so-colled tightly-bound polysomes (TBP) (Davies et al., 1991). This population of polysomes may be released by using buffer $\mathrm{U}$ (Abe et al., 1992) (Figs 1 and 2 ), which is used to solubilize virtually all polysomes from any source.

Animals have been shown to possess three populations of cytoplasmic polysomes, free (FP), membrane-bound (MBP) and cytoskeleton-bound (CBP) (Nielson et al., 1983). This led us to speculate that plants also might contain a population of $\mathrm{CBP}$, but that had been overlooked. Recently, we got much more proofs for the existence of the cytoskeleton-bund-polysomes in plants (e.g. Davies et al., 1988).

Pea stem tissue extracted in buffer A yields over $50 \%$ of polysomes in the supernatant - the FP (Davies et al., 1972), about 30\% released by nonionic detergent - the MBP (Larkins and Davies, 1975) and about $15 \%$ in the detergent insoluble pellet - the TBP (Abe and Davies, 1985). Proportions of polysome populations isolated from barley embryos by using buffer A - releasing FP was similar - about $60 \%$, both in dormant and nondormant caryopses (Fig. 1a). More than 20\% in both cases made fractions of polysomes isolated with the help of buffer A + PTE which releases MBP. A little greater differences were observed after reextraction of pellet by using the buffer $U$, which releases TBP (putative CBP). Proportion of this population of polysomes isolated from embryos of dormant caryopses (after $48 \mathrm{hrs}$ imbibition) was about $16 \%$, whereas after its releasing from dormancy about $10 \%$ (Fig. 1a). The research also included synthesis of polysomal RNA and proteins in vivo (Figs $2 \mathrm{a}$ and $2 \mathrm{~b}$ ). In all cases the highest incorporation of radioactive precursors was observed in fraction TBP (putative CBP). It indicates the high metabolic activity of this fraction of polysomes.

It should be emphasized that polysome formation of all mentioned polysome populations was strongly inhibited in embryos of dormant caryopses during imbibition (Figs $2 \mathrm{a}$ and $2 \mathrm{~b}$ ). In many cases correlation was demonstrated between embryo or cotyledon growth, polysome formation and their total capacity for protein synthesis (e.g. Gwózdź and Deckert, 1989). 


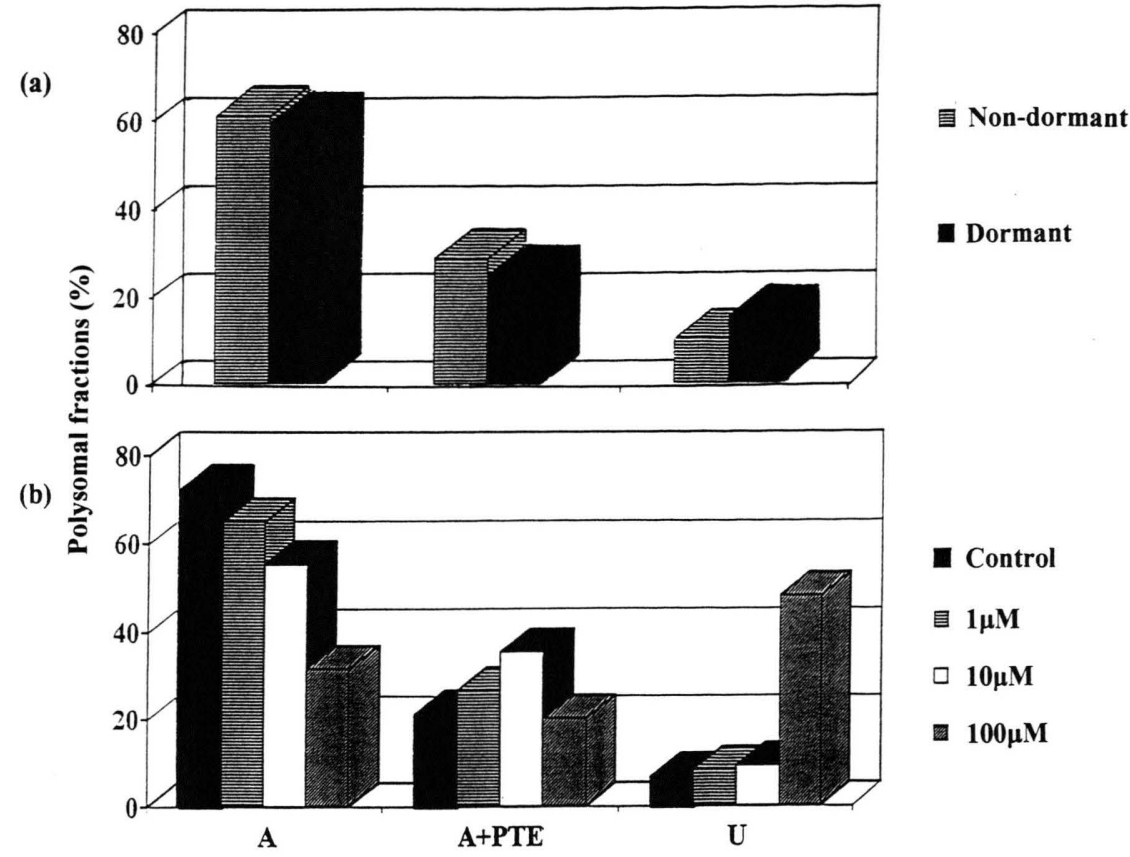

Fig. 1 (a) and (b). The percentage of the polysomal populations (FP, MBP and TBP) in the total ribosomal material, after sequential extraction of barley or triticale embryos in different buffers. Three polysome fractions were extracted from this plant material (FP-free polysomes, MBP-membrane-bound polysomes and TBP-tightly-bound polysomes). Initially the cereal tissue was homogenized in buffer A (200 mm Tris- $\mathrm{HCl}, \mathrm{pH} 8.5,50 \mathrm{~mm} \mathrm{KOAc,} 25 \mathrm{~mm}$ $\mathrm{MgOAc}$ ) - to yield FP. The pellet was extracted sequentially in buffer A + PTE (polyoxyethylene-10-tridecyl ether) - to release MBP. Polysomes retained in pellet were solubilized in buffer U (buffer A supplemented with $2 \%$ PTE, $1 \%$ DOC, 2 mm EGTA and $100 \mu \mathrm{g} \cdot \mathrm{ml}^{-1}$ heparin) - to yield the TBP (putative CBP). (a) Barley embryos (or germs) were isolated from dormant and non-dormant grains after 48 hrs of germination. (b) Triticale grains were germinated in water (control) and in the presence of abscisic acid in following concentrations: $1 \mu \mathrm{M}, 10 \mu \mathrm{M}$ and $100 \mu \mathrm{M}$. After $48 \mathrm{hrs}$ of germination the embryos (or germs) were isolated from the caryopses.

Polysomes formation and translation activity of free, membrane-bound and tightly-bound (putative cytoskeleton-bound) polysomes in embryos of germinating triticale caryopses in the presence of abscisic acid

It has been well documented that abscisic acid (ABA) effects many physiological processes, including seed development, dormancy and germination (Bewely and Black, 1984). In barley aleurone layers ABA suppresses the expression of genes encoding GA induced protein i.e. $\alpha$-amylase and $\beta$-gluconase (Higgins et al., 1982) and also increases the levels of the ABA-induced proteins (Jacobsen and Chandler, 1987; Lin and Ho, 1988).

In our research ABA inhibited ability of triticale caryopses to germinate, proportionally to its concentration. After $48 \mathrm{hrs}$ per cent of germination in particular batches was as follows: control - 95.2 $\pm 1.76 ; 1 \mu \mathrm{M}$ ABA solution $-86.4 \pm 4.32 ; 10 \mu \mathrm{M}$ ABA $-73.4 \pm 4.23$ and $100 \mu \mathrm{m}$ ABA $-54.4 \pm$ 4.56. ABA also influenced accumulation of dry and fresh weight of embryos during germination of caryopses (data not presented). Definitely the highest inhibition of germination processes was observed in embryos of caryopses germinating in ABA solution at $100 \mu \mathrm{m}$ concentration. Medium dry weight of embryo (during $48 \mathrm{hrs}$ of germination) increased $2.91 \mathrm{mg}$ in the control and only $0.32 \mathrm{mg}$ in the sample treated with the highest concentration of ABA.

The highest participation of free polysome populations (FP), isolated by buffer A, was observed both in control sample and in samples treated with $\mathrm{ABA}$ at 1 and $10 \mu \mathrm{m}$ concentration. It was as follows: $73.5,65.1$ and $55.4 \%$ (Fig. 1b). In these three groups was observed the increase of participation of membrane-bound polysome populations iso- 
(a)

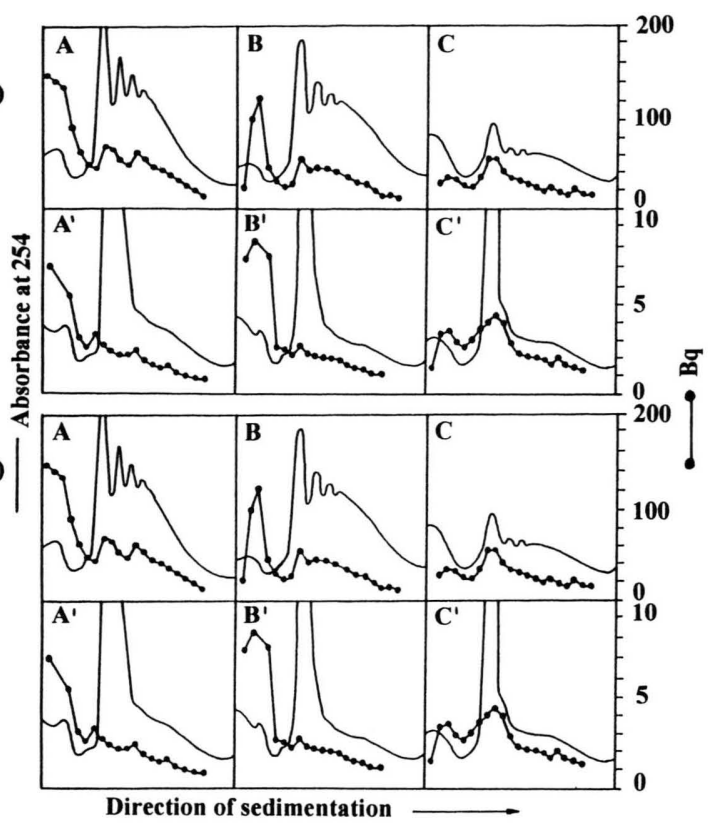

Fig. 2 (a) and (b). Sedimentation in sucrose gradients of polysomes of germinating non-dormant $(\mathrm{A}, \mathrm{B}, \mathrm{C})$ and dormant $\left(\mathrm{A}^{\prime}, \mathrm{B}^{\prime}, \mathrm{C}^{\prime}\right)$ barley caryopses. After initial $48 \mathrm{hrs}$ of germination in water, caryopses were transferred into solution of $\left[{ }^{3} \mathrm{H}\right]$-uridine (a) or $\left[{ }^{14} \mathrm{C}\right]$-amino acids (b) and were labelled for $6 \mathrm{hrs}$. Embryos (or germs) were isolated from grains after $48+6$ hrs germination and three polysome fractions were extracted from this plant material (FP-free polysomes, MBP-membranebound polysomes and TBP-tightly-bound polysomes). Initially the cereal tissue was homogenised in buffer A $(200 \mathrm{~mm}$ Tris- $\mathrm{HCl}, \quad \mathrm{pH} 8.5, \quad 50 \mathrm{~mm}$ KOAc, $25 \mathrm{~mm}$ $\mathrm{MgOAc})$ - to yield FP (A, $\left.\mathrm{A}^{\prime}\right)$. The pellet was extracted sequentially in buffer A + PTE (polyoxyethylene-10-tridecyl ether) - to release $\mathrm{MBP}\left(\mathrm{B}, \mathrm{B}^{\prime}\right)$. Polysomes retained in pellet were solubilized in buffer $\mathrm{U}$ (buffer $\mathrm{A}$ supplemented with 2\% PTE, 1\% DOC, 2 mм EGTA and $100 \mu \mathrm{g} \cdot \mathrm{ml}^{-1}$ heparin) - to yield the TBP - putative CBP $\left(\mathrm{C}, \mathrm{C}^{\prime}\right)$.

lated by buffer A + PTE proportionally to increase of concentrations of abscisic acid. It was in the control group $21 \%$, and in samples treated with $\mathrm{ABA}$ at 1 and $10 \mu \mathrm{M}$ concentrations respectively: 26.6 and $35.4 \%$. Participation of TBP (isolated by buffer $\mathrm{U}$ ) was in these groups very low, no higher than $10 \%$. Other dependence was observed however, in group of caryopses exposed to germination in $100 \mu \mathrm{M}$ concentration of ABA. In embryos of these caryopses (in which processes of germination were inhibited almost completely), the highest participation had population TBP -
$48.2 \%$, lower population FP - 31.6\% and the lowest population MBP - 20.2\% (Fig. 1b).

In next part was defined the percentage of polysomes in the total ribosomal materials (sub-units, monosomes and polysomes) in particular populations of FP, MBP and TBP, extracted from embryos tissue, after $48 \mathrm{hrs}$ of triticale caryopses germination (Table I). The highest participation of polysomes in all studied populations was found in embryo tissue from the control group. Polysomes made up here $81.67 \%$ of total ribosomal material extracted by buffer A (FP), 78.26\% - by buffer A + PTE (MBP) and $56.45 \%$ by buffer U (TBP). Much smaller participation of polysomes was observed in ribosomal fractions isolated from embryos of caryopses treated with ABA. By applying the highest concentration of ABA $(100 \mu \mathrm{M})$, the participation was $31 \%$ in fraction FP, 46.91 in fraction MBP and $19.64 \%$ in fraction TBP (Table I).

In the opinion of Dommes and Van de Walle (1990) and You et al. (1992) during short 2030 min of incubation with labelled amino acids, the vast majority of polysome associated label is in nascent protein. Incorporation of $\left[{ }^{14} \mathrm{C}\right]$-amino acids into nascent polypeptide chains in control sample (after $48 \mathrm{hrs}$ of germination of caryopses $+30 \mathrm{~min}$ of incubation with precursors) was as follows: in fraction isolated by buffer A - 143 (FP), by buffer A + PTE - 700 (MBP), and by buffer U - (TBP) $1421 \mathrm{~Bq} \cdot \mathrm{mg}^{-1}$ of polysomes, whereas in the sample treated with ABA (concentration - $100 \mu \mathrm{M}$ ) was 16, 136 and $204 \mathrm{~Bq} \cdot \mathrm{mg}^{-1}$ of polysomes respectively. The highest incorporation of precursors into newly formed proteins was observed in both examined samples in the last fraction of polysomes, isolated with the help of the buffer U (TBP). In the sample treated with ABA $(100 \mu \mathrm{M})$, the activity of this population of polysomes in forming new proteins in relation to $\mathrm{FP}$ was about 13 times higher. The highest incorporation of $\left[{ }^{3} \mathrm{H}\right]$-uridine into polysomal RNA in the TBP was also found during precocious germination of triticale caryopses (Weidner and Łukaszewicz, 1977). It should be emphasised that protein synthesis with the participation of all mentioned polysome populations was strongly inhibited in embryos of germinating caryopses in the presence of ABA (Table I). These results are in agreement with our earlier research conducted on embryos of germinating wheat caryopses (Weidner et al., 1991). We found that the 
Table I. The percentage of polysomes in the total ribosomal materials (sub-units monosomes and polysomes) of each of examined polysome populations and the incorporation $\left[{ }^{14} \mathrm{C}\right]$-amino acids into polysome fractions of triticale embryos during germination of caryopses. After initial 48 hrs of germination in water or in ABA solutions caryopses were transferred into solution of radioactive precursors and were labelled for 30 min. Embryos (or germs) were isolated from grains after definite germination time and three polysome populations (FP-free polysomes, MBPmembrane-bound polysomes, TBP-tightly-bound polysomes) were extracted from this plant material. Initially the cereal tissue was homogenized in buffer A (200 mm Tris- $\mathrm{HCl}, \mathrm{pH} 8.5,50 \mathrm{~mm} \mathrm{KOAc,} 25 \mathrm{~mm} \mathrm{MgOAc})-$ to yield FP. The pellet was extracted sequentially in buffer A + PTE (polyoxyethylene-10-tridecyl ether) - to release MBP. Polysomes retained in pellet were solubilized in buffer U (buffer A supplemented with $2 \%$ PTE, $1 \%$ DOC, 2 mM EGTA and $100 \mu \mathrm{g} \cdot \mathrm{ml}^{-1}$ heparin) - to yield the TBP (putative CBP).

\begin{tabular}{|c|c|c|c|c|c|c|}
\hline \multirow{3}{*}{ Treatment } & \multicolumn{6}{|c|}{ Buffer } \\
\hline & \multicolumn{2}{|c|}{ A } & \multicolumn{2}{|c|}{$\mathrm{A}+\mathrm{PTE}$} & \multicolumn{2}{|c|}{$\mathrm{U}$} \\
\hline & $\begin{array}{c}\text { polysomes } \\
\%\end{array}$ & $\begin{array}{l}\mathrm{Bq} \cdot \mathrm{mg}^{-1} \\
\text { polysomes }\end{array}$ & $\begin{array}{c}\text { polysomes } \\
\%\end{array}$ & $\begin{array}{l}\mathrm{Bq} \cdot \mathrm{mg}^{-1} \\
\text { polysomes }\end{array}$ & $\begin{array}{c}\text { polysomes } \\
\%\end{array}$ & $\begin{array}{l}\mathrm{Bq} \cdot \mathrm{mg}^{-1} \\
\text { polysomes }\end{array}$ \\
\hline Control & 81.67 & 143 & 78.26 & 700 & 56.45 & 1421 \\
\hline $1 \mu \mathrm{M}$ ABA & 72.67 & - & 71.30 & - & 50.76 & - \\
\hline $10 \mu \mathrm{m} \mathrm{ABA}$ & 64.13 & - & 64.70 & - & 45.79 & - \\
\hline $100 \mu \mathrm{M} \mathrm{ABA}$ & 31.00 & 16 & 46.91 & 136 & 19.64 & 204 \\
\hline
\end{tabular}

$\left[{ }^{3} \mathrm{H}\right]$-leucine incorporation into protein in vitro, by free and membrane-bound polysomes from embryos incubated with ABA $(100 \mu \mathrm{M}$ concentration), was lower in all stages of germination. The synthesis of a $28 \mathrm{kDa}$ peptide was strongly inhibited by ABA, whereas the appearance of others was delayed.

When dormancy was imposed by $100 \mu \mathrm{m}$ ABA the highest participation of population of tightlybound polysomes (TBP) and the highest incorporation of $\left[{ }^{14} \mathrm{C}\right]$-amino acids into nascent polypeptide chains in embryos of triticale caryopses was observed. This finding and also a higher participation of this fraction and their high metabolic activ-

Abe S. and Davies E. (1985), Quantitative analysis of undegraded polysomes from aged pea tissue in the absence of contaminants and artefacts. Plant Cell Physiol. 26, 1499-1507.

Abe S., Ito Y. and Davies E. (1992), Co-sedimentation of actin, tubulin and membranes in the cytoskeleton fractions from peas and mouse 3 T3 cells. J. Exp. Bot. 43, $941-949$.

Adams A., Fey E.G, Pike S. F., Taylorson C.J, White H. A. and Rabin E. R. (1983), Preparation and properties of a complex from rat liver of polyribosomes with components of the cytoskeleton. Biochem. J. 216, 215-26.

Bewley J. D. and Black M. (1994), Seeds. Physiology of Development and Germination ( $2^{\text {nd }}$ edition). Plenum Press, New York.

Bewley, J. D. (1997), Seed germination and dormancy. Plant Cell 9, 1055-1066. ity during germination of dormant barley caryopses, may indicate the significant role of this subpopulation of polysomes (and proteins synthesized by them) in dormancy of cereal caryopses.

\section{Acknowledgements}

This research was supported by European Cooperation in the field of Scientific and Technological Research, COST Project 828 and the State Committee for Scientific Research (KBN), Project SPUB. We thank Prof. Eric Davies (Botany Department, North Carolina State University) for help with methodology and discussion. We also thank Mrs. Alina Szarejko for technical assistance.

Black M. (1991), Involvement of ABA in the physiology of developing and mature seeds. In: Abscisic Acid: Physiology and Biochemistry (Davies W. J. and Jones H. G., Eds). BIOS Scientific Publ. Oxford, UK, pp. $99-124$.

Bray E. A. (1991), Regulation of gene expression by endogenous ABA during drought stress. In: Abscisic Acid: Physiology and Biochemistry (Davies W. J. and Jones H. G., Eds). BIOS Scientific Publ. Oxford, UK, pp. $81-98$.

Davies E., Abe S., Larkins B. A., Clore A. M., Quatrano R. S. and Weidner S. (1998), The role of the cytoskeleton in plant protein synthesis. In: A Look Beyond Transcription: Mechanisms Determining mRNA Stability and Transcription in Plants (Bailey-Serres J. and Gallie D. R., Eds). American Society of Plant Physiologists, Rockville, MD, USA. pp. 115-124. 
Davies E., Fillinham B. D., Ito Y. and Abe S. (1991), Evidence for the existence of cytoskeleton-bound polysomes in plants. Cell Biol. Int. Rep. 15, 973-981.

Davies E., Larkins B. A. and Knight R. H. (1972), Polyribosomes from peas. An improved method for their isolation in the absence of ribonuclease inhibitors. Plant Physiol. 50, 581-584.

Derera N. F. (1990), A perspective of sprouting research. In: Filth International Symposium on Pre-Harvest Sprouting 1989 (Ringlund K., Mosleth E. and Mares J., Eds). Westview Press, Boulder, CO, USA, pp. 3-11.

Dommes J. and Van de Walle C. (1990), Polysome formation and incorporation of new rybosomes into polysomes during germination of the embryonic axis of maize. Physiol. Plant. 79, 289-296.

Dommes J. and Northcote D. H. (1985), The action of exogenous abscisic and gibberellic acids on gene expression in germinating castor beans. Planta, 165, 513-521.

Elder J. H. and Morré D. J. (1978), Synthesis in vitro of intrinsic membrane proteins by free, membranebound, and golgi apparatus-associated polyribosomes from rat liver. Biol. Chem. 251, 5054-68.

Frike U. (1973), Tritosol: a new scintillation cocktail based on Trition-X-100. Anal. Biochem. 63, 555-558.

Gualerzi C. and Cammarano P. (1969), Comparative electrophoretic studies on the protein of chloroplast and cytoplasmic ribosomes of spinach leaves. $\mathrm{Bi}$ ochim. Biophys. Acta 190, 170 - 186.

Gwóźdź E. A. and Deckert J. E. (1989), The formation and translational activity of polysomes from developing lupin seeds. Physiol. Plant. 75, 208-214.

Hesketh J. E. and Pryme I. F. (1991), Interaction between mRNA, ribosomes and the cytoskeleton. Biochem. J. 277, 1-10.

Higgins T. J. V., Jacobsen J. V. and Zwar J. A. (1982), Gibberellic acid and abscisic acid modulate protein synthesis and mRNA levels in barley aleurone layers. Plant Mol. Biol. 1, 208-214.

Jacobsen J. V. and Chandler P. M. (1987), Gibberellins and abscisic acid in germinating cereals. In: Plant Hormones and Their Role in Plant Growth and Development (Davies P. J., Ed.). Martinus Nijhoff Publisher, The Hague, pp. 164-193.

Larkins B. A. and Davies E. (1975), Polyribosomes from peas. V. An attempt to characterize the total free and membrane-bound polysomal population. Plant Physiol. 55, 749-756.

Lenk R., Ransom L., Kaufman Y. and Penman S. (1977), A cytoskeletal structure with associated polyribosomes in HeLa cells. Cell 10, 67-78.
Li B. and Foley M. E. (1997), Genetic and molecular control of seed dormancy. Trends in Plant Science 2, $384-389$.

Lin L.-S. and Ho D. T.-H (1986), Mode of action of abscisic acid in barley aleurone layers. Induction of new proteins by abscisic acid. Plant Physiol. 82, 289-297.

Morris C. F., Moffatt J. M., Sears R. G. and Paulsen G. M. (1989), Seed dormancy and responses of caryopses, embryos and calli to abscisic acid in wheat. Plant Physiol. 90, 643-647.

Nielsen P., Goelz S. and Trachsel H. (1983), The role of the cytoskeleton in eukaryotic protein synthesis. Cell Biol. Int. Rep. 7, 245-254.

Simpson G. M. (1990), Seed dormancy in grasses. Cambridge University Press, Cambridge, UK.

Singh N. K., Nelson D. E., Kuhn D., Hasegawa P. M. and Bressan R. A. (1989), Molecular cloning of osmotin and regulation of its expression by $\mathrm{ABA}$ and adaptation to low water potential. Plant Physiol. 90, 10961101.

Skriver K. and Mundy J. (1990), Gene expression in response to abscisic acid and osmotic stress. Plant Cell 2, 506-512.

St Johnston D. (1995), The intracellular localization of messenger RNAs. Cell 81, $161-170$.

Walker-Simmons M. (1987), ABA levels and sensitivity in developing wheat embryos of sprouting resistant and susceptible cultivars. Plant Physiol. 84, 61-66.

Walker-Simmons M. (1988), Enhancement of ABA responsiveness in wheat embryos by high temperature. Plant Cell Environ. 11, 769-775.

Weidner S. (1987), the effect of ABA and AM0-1618 on the preharvest sprouting of triticale caryopses. Acta Soc. Bot. Pol. 56, 287-301.

Weidner S., Deckert J. and Gwózdz E. (1991), Translational activity of polysomes from embryos during germination of wheat caryopses in the presence of abscisic acid. Acta Physiol. Plant. 13, 175-182.

Weidner S., Łukaszewicz D. (1997), The role of free, membrane-bound polysomes in precocious germination of triticale caryopses. Acta Physiol. Plant. 19, 109-118.

You W., Abe S. and Davies E. (1992), Cosedimentation of pea root polysomes with the cytoskeleton. Cell Biol. Int. Rep. 16, 663-673. 